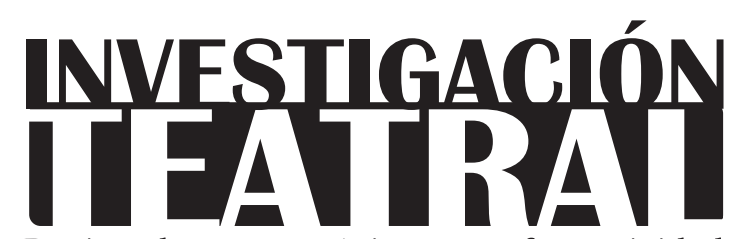

Revista de artes escénicas y performatividad

Vol. 11, Núm. 17

abril-septiembre 2020

Segunda época

ISSN impreso: 1665-8728

ISSN electrónico: 2594-0953

Universidad Veracruzana

In memoriam:

\title{
Juan Tovar Botello (1941-2019)
}

\author{
Gisel Amezcua*
}

*Universidad Veracruzana, México.
e-mail: giselamezcua@gmail.com

Recibido: 04 de febrero de 2020

Aceptado: 06 de febrero de 2020

Doi: $10.25009 /$ it.v11i17.2637 


\section{In memoriam:}

\section{Juan Tovar Botello (1941-2019)}

$\mathrm{H}$ ombre de pocas, pero acertadas palabras, Juan Tovar Botello (23 de octubre de 1941, Puebla- 23 de diciembre de 2019, Tepoztlán, México), además de haber sido novelista, fuiste poeta, dramaturgo, guionista, adaptador y hasta traductor. Pocos saben que tradujiste al español los primeros libros de Carlos Castaneda, tan leídos por los jóvenes de la contracultura mexicana en los años 1970-80. A pesar de carecer de un certificado de estudios, no fuiste un escritor autodidacta, porque maestros tuviste de los mejores. El primero fue Ignacio Ibarra Mazari, director del Teatro Universitario de Puebla, quien te dio a conocer, entre otros autores, a Chéjov; después, Emilio Carballido, primer escritor profesional en leer tus trabajos -ya no digamos en comentarlos detenidamente a vuelta de correo-. Debo confesar que, desde que volaste de la cima del Tepozteco, es que tengo ahogada esta despedida.

Hace más de 20 años que escuché hablar de ti por primera vez. Fueron Emilio Carballido y Flavio González Mello, tu maestro y alumno, quienes me recomendaron Doble vista, un ensayo sobre teoría teatral. ${ }^{1}$ Sin embargo, nunca insinuaron que te lucías con la narrativa; lo primero que leí fue una novelita, Criatura de un día, un librito de lo más exquisito y delicado.

Así fue que te conocí, después, como mi maestro, también de varias generaciones del CCC (Centro de Capacitación Cinematográfica). Fuiste de los pocos escritores con esa pro-

1 Desde su título, Doble vista es un monstruo bicéfalo: un ensayo de teoría teatral y una crónica de praxis dramatúrgica. Los temas que abarca: aristotelismos, teoría de géneros, crónica de la propia experiencia, teatro y literatura, guión cinematográfico, son sometidos a un lúcido examen mediante una prosa espléndida. Ver Tovar, Juan. Doble vista. México: El Milagro, 2010. 
INVESTIGACIÓNTEATRAL

Revista de artes escénicas y performatividad

Vol. 11, Núm. 17

abril-septiembre 2020
In memoriam:

Juan Tovar Botello (1941-2019)

Gisel Amezcua

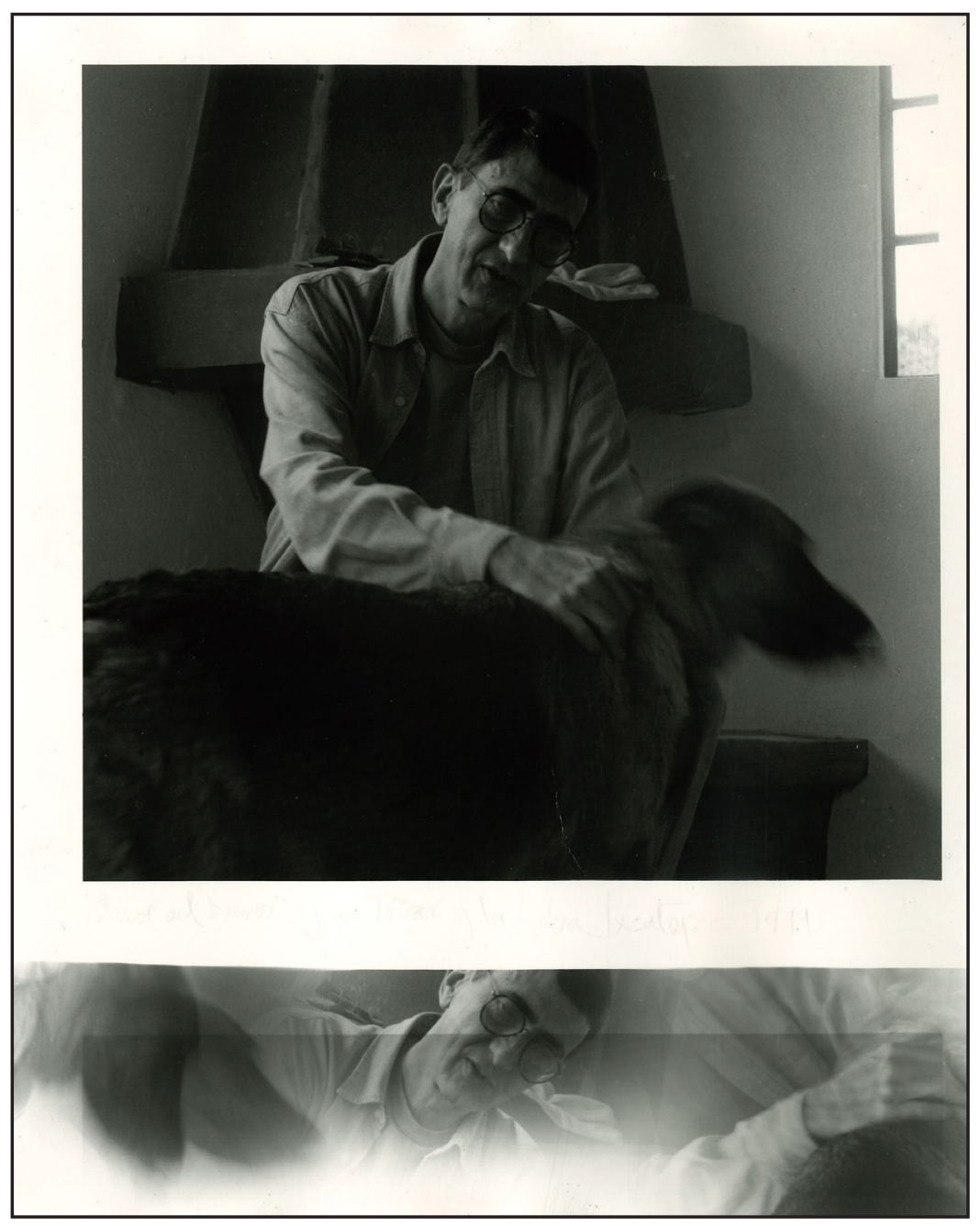

"Amor del bueno. Juan Tovar y la Loba. Ixcatepec, 1999". Estudio en Ixcatepec, Tepoztlán (Morelos, México). Fotografía de Ricardo Vinós.

digiosa capacidad de ver el potencial ajeno; de modo humilde y asertivo en tus consejos, lograste ser un maestro inspirado e inspirador. Durante tres años, cada viernes, llegabas al salón de clase con la sonrisa de haber descifrado la ecuación que resolvía la trama de algún compañero. Recordabas a detalle pizcas de obras; decías palabras justas y sinceras porque, si no te gustaba, era fácil verlo reflejado en tu rostro. ¡Qué honestidad! Sabiduría decantada por el tiempo, consejas, discusión y claves: "Tus letras saldrán al mundo cuando sea necesario", fue la recomendación que me diste.

¡Gran Maestro! Siempre pensabas en las estructuras de tus historias o las ajenas, que no dejaban de moverse por tu mente. Te fuiste llenando de murmuraciones que te llega- 
ban por doquier y que anotabas en un cuaderno para luego irlas escribiendo cada vez más lenta y laboriosamente. Sintiéndote tímido y tartamudo, como en la vida real, ensayabas audacias formales, experimentos de fondo, y corregías hasta el cansancio. Sin embargo, tu genial corrección a la teoría de Luisa Josefina Hernández resuelve cualquier discusión sobre un tema estéril que nos ocupó demasiado tiempo: "Los siete géneros dramáticos son tres, la tragicomedia".

Supusiste que tus lectores se habían olvidado de ti. Así lo confesaste el día de tu premiación en Bellas Artes, en el 2018, cuando afirmaste que: "No lo esperaba, sobre todo porque pensé que ya se habían olvidado de mí. Es un reconocimiento muy importante, sin duda alguna. Eso me emociona: estoy muy agradecido con los responsables de ello". ${ }^{3}$ Estabas conmovido porque sabías perfectamente que tú no pertenecías a ningún grupo ni generación literaria y probablemente tuvimos dificultad para ubicarte entre las tendencias narrativas discernibles, porque abarcaste todos los géneros y en todos lograste brillar por tu estilo. Por eso, todos te hemos admirado. "Siendo dramaturgo, cuentista, periodista, guionista y traductor, creo que en la decisión de darme la Medalla Bellas Artes se contempla toda mi obra, pero pienso que pesa más la faceta de dramaturgo. El año pasado (2017) se publicó el primer volumen de mi Teatro reunido I y me parece que esto pudo haber tenido cierta influencia". ${ }^{4}$

Las historias se me acumulan, y llega a parecer que no me alcanzará el día para contarlas todas, ya no digamos para escribir este In memoriam. Fuiste un gran transgresor. Tu obra perdurará por años, misma que ahora te acompaña en ese tu camino. Hasta siempre, Juan Tovar Botello. Sólo se va tu cuerpo, aquí permanecen tus letras y legado.

2 Reyes Palacios, Felipe. "Cura y locura de Juan Tovar: Entre Aristóteles, Artaud y Luisa Josefina Hernández". Latin American Theatre Review, vol. 41, núm. 1, 2007, pp. 99-110.

3 “Juan Tovar recibe Medalla Bellas Artes 2018”. El Universal, 26 de julio de 2018, www.eluniversal.com.mx/ cultura/juan-tovar-recibe-medalla-bellas-artes-2018, consultado el 6 de febrero de 2020.

4 "Juan Tovar recibió la Medalla Bellas Artes y la dedica al teatro mexicano". Aristegui Noticias, Aristegui Noticias Network, 26 de julio de 2018, aristeguinoticias.com/2607/kiosko/juan-tovar-recibio-la-medalla-bellas-artes-y-la-dedica-al-teatro-mexicano, consultado el 6 de febrero de 2020. 